\title{
The Resistance of Fiber-reinforced Concrete with Steel Fibers and CFRP to Drop-weight Impact
}

\author{
Ali Kheyroddin ${ }^{1 *}$, Hamed Arshadi ${ }^{1}$, Javad Khedri \\ ${ }^{1}$ Faculty of Civil Engineering, Semnan University, Semnan, 19111-35131, Iran \\ 2 Faculty of Civil Engineering, Higher Education Institute of Roshd Danesh, Semnan, 44, Iran \\ * Corresponding author, e-mail: kheyroddin@semnan.ac.ir
}

Received: 09 November 2020, Accepted: 29 January 2021, Published online: XX Xxxxxx 2021

\begin{abstract}
In this paper, the effects of macro-synthetic steel fibers and bidirectional carbon fiber-reinforced polymers (CFRPs) on the impact resistance of concrete specimens were studied. 54 concrete cylindrical specimens with different compressive strengths (20, 30, and $40 \mathrm{MPa}$ ) and with different fiber content ratios (0 \%, $1 \%, 1.5 \%$, and $2 \%)$ were tested under impact loading. Half of these specimens were tested with the CFRP wrapping. The specimens were subjected to weight (46.7 and $66.8 \mathrm{~kg}$ ) dropping at a height of $1.62 \mathrm{~m}$. The process of weight dropping was continued until $30 \%$ weight loss in the specimens was observed and the number of weight droppings related to this loss was recorded. Results indicated that the impact resistance of the concrete specimens (corresponding to the number of weight droppings) increased by using steel fibers or CFRP wrapping, separately. However, the results demonstrated that the specimens wrapped with the CFRP sheets had much further impact resistance than the FRCs without wrapping. Finally, the results showed that the greater the compressive strengths of the concrete, the better the impact resistance.
\end{abstract}

Keywords

drop-weight impact, steel fibers, carbon fiber-reinforced polymer (CFRP) wrapping, impact resistance, damage patterns

\section{Introduction}

Cement has been among the prevailing and favorable materials to build structures during recent years due to their various profits such as their low price and less consecutive complexity (in comparison to steel), less sensitivity to fire, and so on $[1,2]$. However, the disadvantage of reinforced concrete is their less strength-to-weight ratio than that of the steel materials [3]. This phenomenon led to an increase in material consumption and the dimension of structural members. Thus, researchers have been studying the production and application of higher-strength materials (steel bars and concrete) [4-6]. However, using higher-strength materials have deficiencies like a possible decrease in the ductility and energy dissipation of the Reinforced concrete (RC) structures [7, 8]. Furthermore, cracking is one of the most important phenomena that must be restricted in the RC members. On the other hand, despite the clear advantages and necessity of concrete as a building material, its production and use cannot be considered environmentally friendly or sustainable. This is mainly due to cement content and its current production process that leads to a vast $\mathrm{CO} 2$ emission. $\mathrm{CO} 2$ emission considerably expedites the global-warming crisis [9]. Regarding these premises, fiber-reinforced concrete (FRC) was proposed by researchers as a solution to some of them. FRC is concrete with short fibers, uniformly propagated in different directions. Since the fibers are scattered in all directions in concrete, the fibers create joints and prevent crack expansion. Therefore, fiber strands are significantly efficient in limiting crack widths and increasing their durability. The traits of FRCs are a function of fiber types, fiber shape, fiber orientation, fiber amounts, fiber length, fiber diameter, fiber aspect ratio (length to diameter ratio), and so forth. There are various types of fibers such as natural, steel, synthetic, and glass ones. The fibers increase impact resistance, fatigue resistance, decrease cracking related to plastic shrinkage (which ends up an increase in the residual post-cracking flexural resistance), shear resistance, and energy absorption of RC structures. FRCs have several applications in pavements, precast structural elements, the lining of tunnels, etc [10]. The main reason behind the introduction of the steel fibers was to minimize shear reinforcement bars, expedite the construction process, and increase the residual 
strength of the concrete to make it more ductile. Steel fibers are the most popular fibers used in the FRCs. Steel fibers improve structural strength, impact behavior, abrasion resistance, freeze-thaw resistance.

Existing structures need retrofitting because of such cases as overloading, strength deterioration, and structural damages. Applying fiber-reinforced polymer (FRP) is one of the novel retrofitting approaches in RC structures. Retrofitting with FRPs is performed due to a variety of purposes including bending and shear strength improvement $[11,12]$. FRP retrofitting method is very simple and swift. It can also improve the dynamic resistance of existing structural elements. Furthermore, the FRPs increase the stiffness, strength, energy absorption, and ductility of RC elements subjected to static loading [13]. They make fewer troubles with the serviceability of structures and do not stop their activity. The retrofitting performance of FRPs can be evaluated by experimental and analytical methods (such as incremental dynamic analysis, endurance time method, time-history analysis, etc.) $[14,15]$. It must be mentioned that FRPs are composite materials made of a polymer matrix reinforced with fibers [16]. The process of FRP production has two different phases: productions of the fibrous materials, then bonding the fibrous materials with the matrix. FRPs can have different shapes as laminates, tubes, rods, etc. They can be either multi-directional or uni-directional, which can influence their performance significantly. FRPs can either be bonded with an epoxy adhesive to the surface of a concrete or can be cast in as rebars or even as fibers. FRPs as sheets can be bonded to the concrete, for example by wrapping around columns or bonding to the beams using an epoxy adhesive. The fibers are glass (in glass fiber-reinforced polymers, GFRPs), carbon (in carbon fiber-reinforced polymers, CFRPs), aramid (in aramid fiber-reinforced- polymers, AFRPs), or basalt. Besides, the polymer can be an epoxy, vinyl ester, or polyester thermosetting plastic.

The majority of both land-based and off-shore, critical, and residential structures can be subjected to extreme actions such as impacts induced by extreme wind action, vehicle and vessel collisions, or explosions. It must be reminded that extreme wind actions occur more and more often because of the climate change crisis which causes extreme impact/dynamic effect on the structures (many times even larger than the structures are designed for). Then, it is vital to construct structures with acceptable impact resistance. However, there are not enough studies on the effects of FRPs and fibers on the impact resistance of RC elements. Upendra Mahendra et al. [17] experimentally investigated the flexural and shear behavior of CFRP and GFRP retrofitted beams. They resulted that the CFRP retrofitted specimens showed better shear and flexural behavior. Sohaib et al. [18] researched the effects of polypropylene fibers on the compressive and tensile strength of concrete specimens. They concluded that the optimum ratio of polypropylene fiber was $1.5 \%$ based on the cement weight. The addition of a small amount of polypropylene improved the mechanical properties of concrete. Guerini et al. [19] focused on the effects of steel and macro-synthetic fibers on concrete properties such as workability, compressive strength, air content, and so on. They manifested that using fibers increased air content, steel fibers decreased concrete workability further than polypropylene ones, and polypropylene fibers increased the toughness of concrete more than steel fibers. Bonin and Neumaier [10] experimentally investigated the effect of polymer binder on the pull-out force of macro-fibers in concrete. They indicated that there was a strong interaction between the macro-fibers and the polymer used. Kazmi et al. [20] experimentally studied the effects of macro-synthetic fibers on the fracture behavior of recycled-aggregate concrete (RAC). The results indicated that using macro-synthetic fibers increased the tensile strength of RAC specimens. Mousavi and Shafei [21] experimentally investigated the behavior of hybrid-steel reinforced concrete slabs under impact loading. They showed that the FRP materials reduced damage and steel increased energy absorption. Sadraie et al. [22] numerically and experimentally investigated the dynamic response of RC slabs with steel and GFRP bars exposed to impact. The results demonstrated that an increase in the steel rebar amount or the slab thickness enhanced the impact resistance of the RC slabs. American society for testing and materials published D7136/D7136M-12 as the standard test approach to evaluate the damage resistance of FRP composite specimens under weight-dropping [23]. Zhang et al. [24] researched the impact response of hybrid-basalt macro-synthetic polypropylene fiber-reinforced concrete (BSFRC). They also suggested a constitutive model for the hybrid FRC. Andrew et al. [25] studied the influential parameters on the impact behavior of FRP matrix composite materials. They introduced useful methods to improve the impact behavior of composites.

As mentioned in the paragraphs above, using FRC along with wrapping concrete members by FRPs can significantly affect their impact resistance. However, there are not sufficient experimental studies about this issue. 
Thus, in this paper, the effects of macro-synthetic steel fibers (with the production name of MEX-200) and CFRPs on the impact behavior of concrete specimens were studied. Fifty-four concrete specimens with different compressive strengths $(20,30$, and $40 \mathrm{MPa}$ at 28 days) and with different fiber ratios $(0 \%, 1 \%, 1.5 \%$, and $2 \%)$ were constructed and tested under impact loading. Only half of these specimens were tested with CFRP wrapping. The specimens were subjected to weight dropping $(46.7 \mathrm{~kg}$ and $66.8 \mathrm{~kg}$ ). After crashing the weight on the specimens, the weight of the specimens was measured and compared to their weights before crashing. This process of weight dropping was continued until the destruction of the specimens (30\% weight loss) was observed. The number of weight releasing necessitated to $30 \%$ weight loss (representative to the impact resistance) was counted. Results indicated that the impact resistance of the concrete specimens increased by an increase in steel fiber content ratios or CFRP wrapping. However, the results indicated that the specimens wrapped with the CFRPs had much better impact behavior than the FRC specimens without the CFRP wrapping. Finally, the experimental observations demonstrated that the greater the compressive strengths of the specimens, the greater the impact resistance.

\section{Experimental method \\ 2.1 Concrete characteristics}

The specimens were constructed using the $\mathrm{C} 20, \mathrm{C} 30$, and C40 grade concrete. The cylindrical casts were used with dimensions of $150 \times 300 \mathrm{~mm}^{2}$. All the weights of the concrete parts (e.g. sand, gravel, cement, and water) were measured by a digital weight measuring device to reach the objective compressive strengths specified in the concrete mix design. Besides, the concrete had normal weight aggregates with a nominal maximum size of $10 \mathrm{~mm}$. Also, the concrete was built using Portland cement type 2 with a water-cement ratio of 0.5 . It must be added that the ratios of the fibers $(1,1.5$, and $2 \%)$ were measured based on the weight of cement. The concrete mixtures were poured into the cylindrical casts in three steps, and the concrete was compacted in each step by inflicting 25 impacts using steel rods to drive out air bubbles from concrete. The specimens were subjected to curing for 28 days (by providing enough moisture, temperature, and time), and then, two specimens with each compressive strength were exposed to the standard uniaxial compression tests. The compressive strengths of the specimens were $20.83,31.05$, and $41.27 \mathrm{MPa}$ at 28 days for the $\mathrm{C} 20, \mathrm{C} 30$, and $\mathrm{C} 40$ grade concrete, respectively.

\subsection{Macro-synthetic steel fibers (MEX-200)}

In this study, macro-synthetic steel fibers with the product name MEX-200 which was in the group of steel fibers were used. It must be noted that the 'MO' acronym name stands for the 'macro' word. As shown in Fig. 1, these fibers had jagged shapes that improve their effects on the behavior of the specimens. Table 1 shows the specifications of steel fibers (MEX-200) used in this study.

\subsection{CFRP confinement}

Bidirectional CFRP wrapping which was known by the commercial name of Kor-GFW160 was circumferentially attached to the 24 of the specimens (plain and fiber-reinforced concrete) by epoxy resin in this study. It must be noted that there was a complication in the tests of the cylindrical specimens due to their confinement, because the specimens could be completely crashed inside and still be kept together because of the confinement, especially in the case of using small specimens and the gravels greater than $16 \mathrm{~mm}$. For this reason, the specimens with the dimension of $150 \times 300 \mathrm{~mm}^{2}$, coarse aggregates with the maximum size of $10 \mathrm{~mm}$, and CFRPs with low thicknesses were used in this study. It was important to keep the

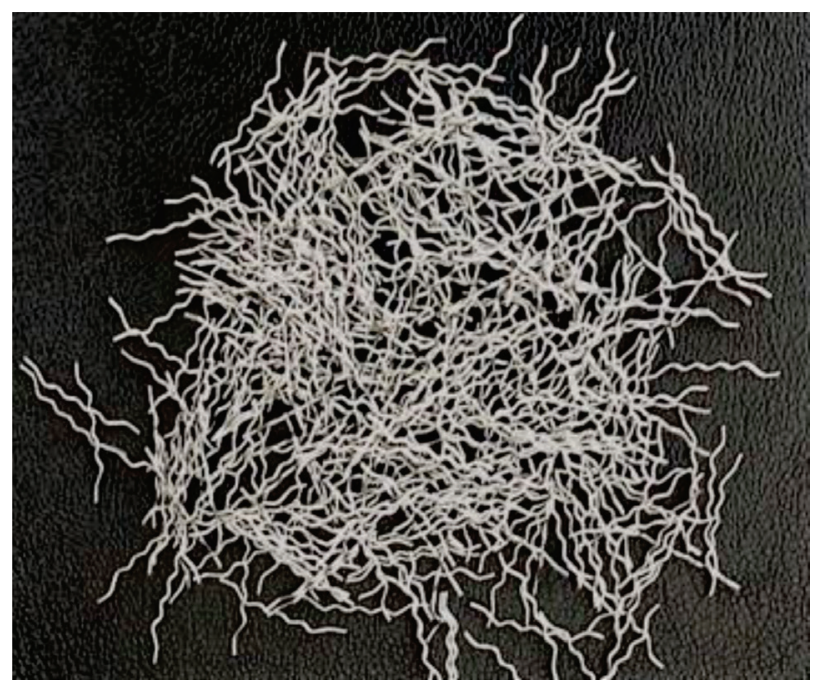

Fig. 1 Macro-synthetic steel fibers (MEX-200)

Table 1 Physical and mechanical specifications of the steel fibers (MEX-200)

\begin{tabular}{lc}
\hline Fiber lengths $(\mathrm{mm})$ & 40 \\
Tensile strength $(\mathrm{MPa})$ & 450 \\
Elasticity module (Young's module) $(\mathrm{GPa})$ & 6.3 \\
Melting temprature $\left({ }^{\circ} \mathrm{C}\right)$ & 160 \\
Combustion temprature $\left({ }^{\circ} \mathrm{C}\right)$ & 450 \\
Colour & Natural \\
\hline
\end{tabular}


Table 2 Mechanical characteristics of the CFRP sheets

\begin{tabular}{lcccccc}
\hline Product name & Fiber types & Fiber strength (MPa) & Fiber stiffness $(\mathrm{GPa})$ & Areal weight $\left(\mathrm{g} / \mathrm{m}^{2}\right)$ & Fiber thickness $(\mathrm{mm})$ & Style \\
\hline Kor-GFW160 & E-carbon & 4900 & 230 & 160 & 0.09 & Woven UD \\
\hline
\end{tabular}

thickness of the wrapping thin and scatter the fibers in different directions. Table 2 shows the mechanical characteristics of the CFRP sheets. It must also be noted that CFRP sheets have linear elastic behavior up to their failure state.

\subsection{Test setup}

In these experiments, a device like a truss that was put on a strong floor was used to impose impacts on the specimens (designed based on the experimental studies of Pham et al. [26] and Sadraie et al. [22]). The height of this device was $3.1 \mathrm{~m}$ and its width at the bottom was $2.5 \mathrm{~m}$. The weights were fixed on the top of the specimens (at a height of $1.6 \mathrm{~m}$ ) using ropes that went through a spool that was attached to the mid-span of the upper beam of this device. The dimensions of the strong floor were $2 \times 3 \mathrm{~m}^{2}$. The strong floor was constructed by $\mathrm{C} 40$ concrete which its surroundings were covered by steel plates with a width of $300 \mathrm{~mm}$ and a thickness of $20 \mathrm{~mm}$. These steel plates were used to increase the strength of the strong floor and weld the truss-like device to it. Fig. 2 shows the experimental setup in this study. Fig. 3 and Fig. 4 indicate the weights and strong floor used in the experiments.

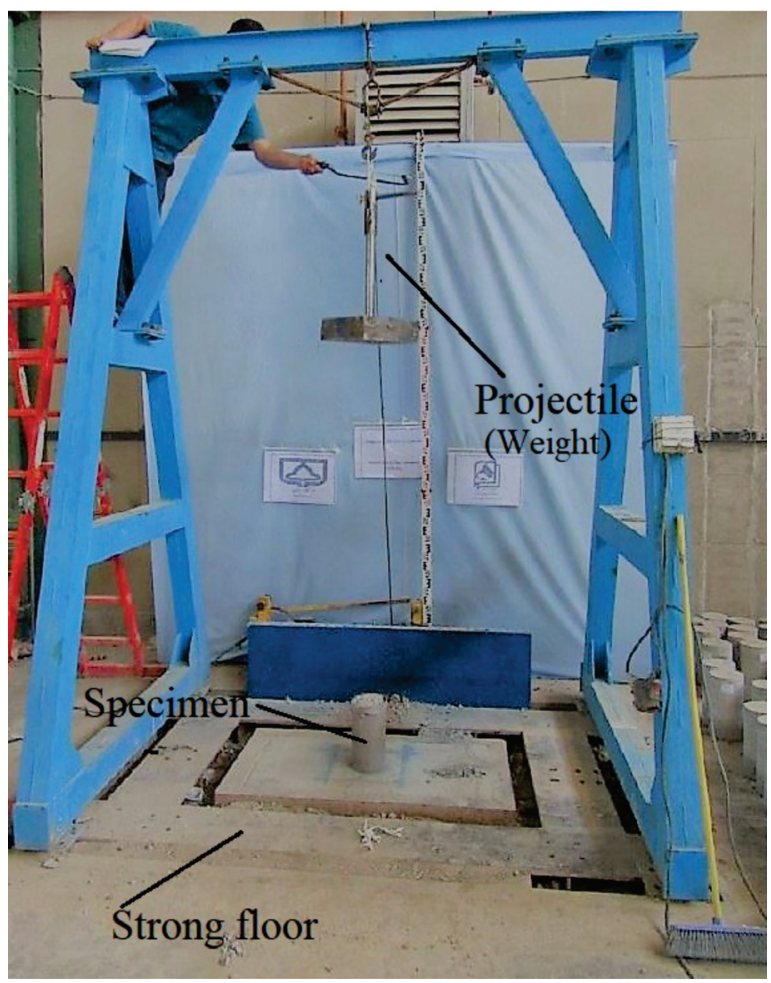

Fig. 2 Experimental setup
The weights (weights) were square-shaped with the dimensions of $300 \times 300 \mathrm{~mm}^{2}$ and made of cast iron. The reason for choosing this shape for the weights and dimensions is to impose impact loads on the specimens more uniformly. Using the steel disc and neoprene pad on the specimens is the other solution to uniformly impose impact loads on the specimens. These weights have hollow sections in their center to pass steel rods through them to add weights to each other. The weights were fixed on the top of the specimens in a way that the centers of the weights and specimens coincide with each other using

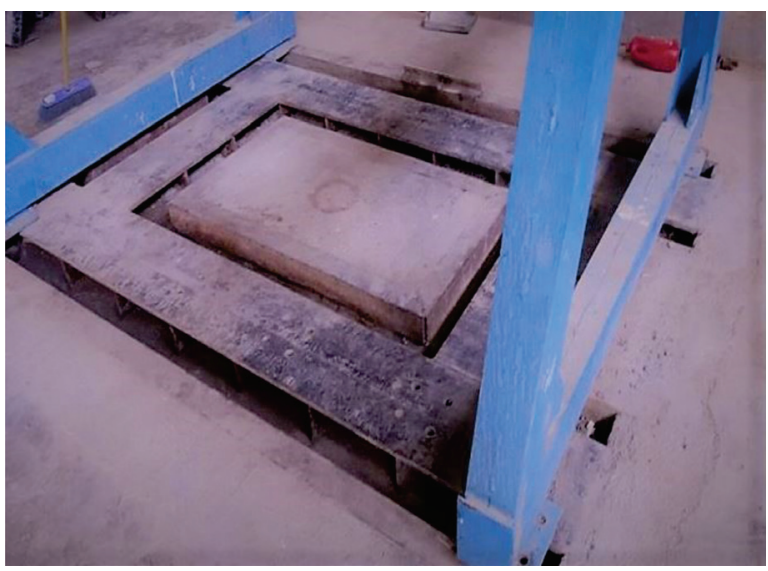

Fig. 3 Strong floor constructed for the experiments

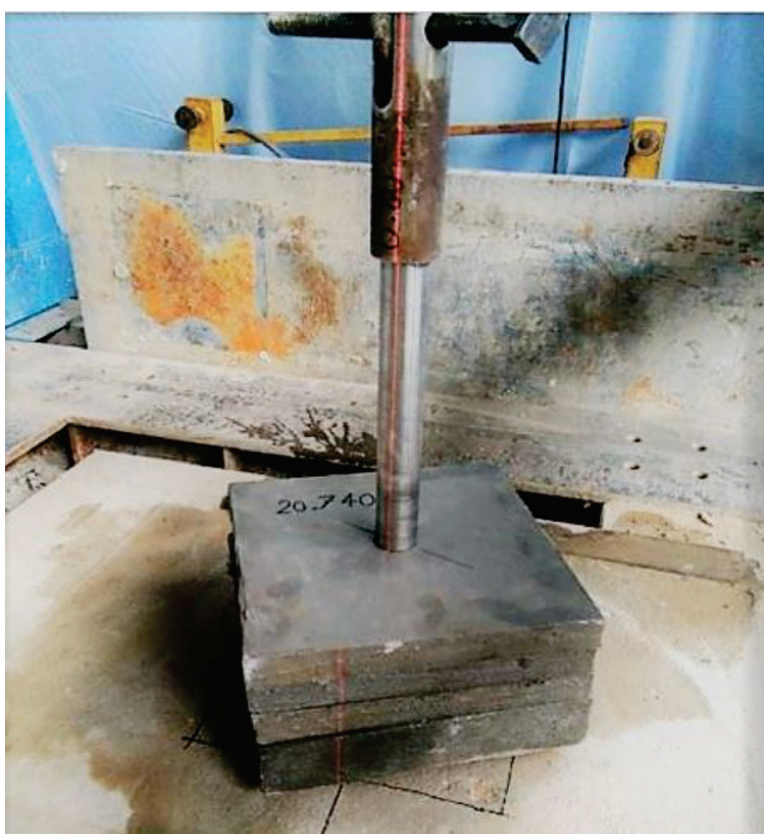

Fig. 4 Weights used in the experiments 
laser plummet, and then the ropes were cut. After the concrete specimens were situated on the strong floor under the weights $(46.7 \mathrm{~kg}$ and $66.8 \mathrm{~kg}$ ). The weights were released by cutting the ropes on the concrete specimens. The reason behind the cutting of the rope was to prevent too much manual handling. After crashing the weights on the concrete specimens, the weight of the specimens was measured and compared to their initial weights. This process of weight-dropping was continued until the destruction of the specimens (30\% weight loss) was observed [27]. The number of weight-dropping necessitated to $30 \%$ weight loss (representative to the impact resistance) was recorded.

The impact principle has an application in describing the behavior of things in the case of a collision with each other. Great impact forces are produced due to collisions during a short duration of time. It must be noted that the impact phenomenon is very complicated and includes material deformation, return to the initial state, heat and sound production, etc. Small changes in the impact condition may end up great changes in the consequences. Thus, experimental studies can be more reliable than only analytical and numerical investigations into the impact phenomenon.

The first principle of Newton's force laws is as Eq. (1):

$$
F=m \times a,
$$

where $F$ is inertial force, $m$ is the germ, and $a$ is acceleration. The gravitational acceleration is constant and nearly equal to $9.81 \mathrm{~m} / \mathrm{S}^{2}$ near the earth's surface. The impact-induced forces due to the collision of the 46.7 and $66.8 \mathrm{~kg}$ weights on the specimens were approximately 457.66 and $654.64 \mathrm{~N}$, respectively, (which were imposed on the specimens after each weight-dropping). It must be mentioned that the exact amount of the induced impact forces is not constant, and yet is dependent on parameters such as time, the inertia of the bodies, their rigidity, and deformation. On the other hand, the energy amount imposed on a steel ball with a diameter of $63.5 \mathrm{~mm}$ according to the ACI 544.1R-96 suggestions [28] regarding releasing a hammer with a weight of $4.45 \mathrm{~kg}$ from a height of $0.475 \mathrm{~m}$ is calculated as follows (Eq. (2)):

$U=m \times g \times h$,

where $m$ is the germ, $g$ is the gravitational acceleration (equal to $9.81 \mathrm{~m} / \mathrm{S}^{2}$ near the earth's surface), and $h$ is dropping height. The imposed energy suggested by ACI 544.1R-96 is computed as follows:

$U_{A C I}=4 / 45 \times 9 / 8 \times 0 / 475=20 / 71(J)$.
As for the 46.7 and $66.8 \mathrm{~kg}$ weights, the imposed energies on the concrete specimens are $732.25(\mathrm{~J})$ and 1074.42 J, respectively. Thus, the imposed energies of the 46.7 and $66.8 \mathrm{~kg}$ weights were 35.35 and 50.57 times the imposed energy of impact experiments suggested by the ACI 544.1R-96 [28], respectively.

\subsection{Specimens}

Although the CFRP confinement improves the impact resistance of the specimens, the effects of macro-synthetic steel MEX-200 (MO) fibers and CFRPs on the impact resistance of the cylindrical specimens exposed to axially impact loading were less investigated in the previous studies. Mastali et al. used cylindrical disc specimens with a dimension of $150 \times 75 \mathrm{~mm}^{2}$ in their experiments [27, 29]. In this study, specimens were constructed with a dimension of $150 \times 300 \mathrm{~mm}^{2}$ due to the considerations related to the test setup. In this study, 55 cylindrical specimens with the compressive strengths of 20,30, and $40 \mathrm{MPa}$ with the fiber content rations of $0 \%, 1 \%, 1.5 \%$, and $2 \%$ were constructed. The content ratios of fibers were the ratios of fiber's weights to that of cement. Moreover, twenty-four of these specimens were confined by CFRP wrapping. Six of the specimens without wrapping were tested under a unidirectional compression test to find their compressive strengths. As for the specimens subjected to the impact loading, half of them were subjected to the dropping of the $46.7 \mathrm{~kg}$ weights, and the other half subjected to the dropping of the $66.8 \mathrm{~kg}$ weights. Table 3 shows the specification of the specimens and the test types where they were used. It must be reminded that 6 more specimens were constructed and used for the unidirectional compression tests.

\section{Experimental results and discussion 3.1 Impact numbers}

The specimens were weighed using a digital weightmeasuring device after dropping the weights on them to determine whether the destruction state (which is tantamount to the $30 \%$ weight-loss state) occurred or not. The more the impact numbers, the better and greater the impact resistance of the specimens. Fig. 5 demonstrates the states of the unconfined C30 FRC specimen with the $1.5 \%$ steel fibers exposed to the drop of the $46.7 \mathrm{~kg}$ weights. Furthermore, Fig. 6 shows the failure states of the $\mathrm{C} 30$ confined FRC specimen with the $1.5 \%$ steel fibers under the 46.7 and $66.8 \mathrm{~kg}$ weight-releasing. As illustrated in the below figures, the unconfined FRC specimens had more damages in their body and bottom portions along 
Table 3 Characteristics and experiments of the concrete specimens

\begin{tabular}{|c|c|c|c|c|c|c|}
\hline Number & Specimen name & $\begin{array}{l}\text { Compressive strength } \\
\text { grade }(\mathrm{MPa})\end{array}$ & Fiber ratios (\%) & Wrapping & $\begin{array}{l}\text { Specimen weight } \\
(\mathrm{kg})\end{array}$ & $\begin{array}{l}\text { Projectile weight } \\
(\mathrm{kg})\end{array}$ \\
\hline 101 & $\mathrm{C} 20$ & 20 & 0 & - & 12.26 & 46.7 \\
\hline 102 & $\mathrm{C} 20$ & 20 & 0 & - & 12.02 & 66.8 \\
\hline 103 & C200-CFRP & 20 & 0 & CFRP & 12.66 & 46.7 \\
\hline 104 & C20-CFRP & 20 & 0 & CFRP & 12.56 & 66.8 \\
\hline 105 & $\mathrm{C} 30$ & 30 & 0 & - & 12.42 & 46.7 \\
\hline 106 & $\mathrm{C} 30$ & 30 & 0 & - & 12.68 & 66.8 \\
\hline 107 & C30-CFRP & 30 & 0 & CFRP & 12.58 & 46.7 \\
\hline 108 & C30-CFRP & 30 & 0 & CFRP & 12.48 & 66.8 \\
\hline 109 & $\mathrm{C} 40$ & 40 & 0 & - & 12.68 & 46.7 \\
\hline 110 & $\mathrm{C} 40$ & 40 & 0 & - & 12.56 & 66.8 \\
\hline 111 & C40-CFRP & 40 & 0 & CFRP & 12.62 & 46.7 \\
\hline 112 & C40-CFRP & 40 & 0 & CFRP & 12.5 & 66.8 \\
\hline 113 & C20-MO1\% & 20 & 1 & - & 11.82 & 46.7 \\
\hline 114 & $\mathrm{C} 20-\mathrm{MO} 1 \%$ & 20 & 1 & - & 11.94 & 66.8 \\
\hline 115 & C20-CFRP-MO1\% & 20 & 1 & CFRP & 12.06 & 46.7 \\
\hline 116 & C20-CFRP-MO1\% & 20 & 1 & CFRP & 12.56 & 66.8 \\
\hline 117 & C20-MO1.5\% & 20 & 1.5 & - & 12 & 66.8 \\
\hline 118 & C20-MO1.5\% & 20 & 1.5 & - & 11.94 & 46.7 \\
\hline 119 & C20-CFRP-MO1.5\% & 20 & 1.5 & CFRP & 12.06 & 46.7 \\
\hline 120 & C20-CFRP-MO1.5\% & 20 & 1.5 & CFRP & 12.49 & 66.8 \\
\hline 121 & $\mathrm{C} 20-\mathrm{MO} 2 \%$ & 20 & 2 & - & 11.34 & 46.7 \\
\hline 122 & $\mathrm{C} 20-\mathrm{MO} 2 \%$ & 20 & 2 & - & 11.3 & 66.8 \\
\hline 123 & C20-CFRP-MO2\% & 20 & 2 & CFRP & 12.51 & 46.7 \\
\hline 124 & C20-CFRP-MO2\% & 20 & 2 & CFRP & 12.38 & 66.8 \\
\hline 125 & $\mathrm{C} 30-\mathrm{MO} 1 \%$ & 30 & 1 & - & 11.52 & 46.7 \\
\hline 126 & C30 -MO1\% & 30 & 1 & - & 11.48 & 66.8 \\
\hline 127 & C30-CFRP-MO1\% & 30 & 1 & CFRP & 12.4 & 46.7 \\
\hline 128 & C30-CFRP-MO1\% & 30 & 1 & CFRP & 12.54 & 66.8 \\
\hline 129 & C30-MO1.5\% & 30 & 1.5 & - & 11.56 & 46.7 \\
\hline 130 & C30-MO1.5\% & 30 & 1.5 & - & 11.6 & 66.8 \\
\hline 131 & C30-CFRP-MO1.5\% & 30 & 1.5 & CFRP & 12.51 & 46.7 \\
\hline 132 & C30-CFRP-MO1.5\% & 30 & 1.5 & CFRP & 12.58 & 66.8 \\
\hline 133 & $\mathrm{C} 30-\mathrm{MO} 2 \%$ & 30 & 2 & - & 11.66 & 46.7 \\
\hline 134 & $\mathrm{C} 30-\mathrm{MO} 2 \%$ & 30 & 2 & - & 11.36 & 66.8 \\
\hline 135 & C30-CFRP-MO2\% & 30 & 2 & CFRP & 12.58 & 46.7 \\
\hline 136 & C30-CFRP-MO2\% & 30 & 2 & CFRP & 12.32 & 66.8 \\
\hline 137 & $\mathrm{C} 40-\mathrm{MO} 1 \%$ & 40 & 1 & - & 12.18 & 46.7 \\
\hline 138 & $\mathrm{C} 40-\mathrm{MO} 1 \%$ & 40 & 1 & - & 12.12 & 66.8 \\
\hline 139 & C40-CFRP-MO1\% & 40 & 1 & CFRP & 12.34 & 46.7 \\
\hline 140 & C40-CFRP-MO1\% & 40 & 1 & CFRP & 12.5 & 66.8 \\
\hline 141 & C40-MO1.5\% & 40 & 1.5 & - & 11.8 & 46.7 \\
\hline 142 & $\mathrm{C} 40-\mathrm{MO} 1.5 \%$ & 40 & 1.5 & - & 11.86 & 66.8 \\
\hline 143 & C40-CFRP-MO1.5\% & 40 & 1.5 & CFRP & 12.55 & 46.7 \\
\hline 144 & C40-CFRP-MO1.5\% & 40 & 1.5 & CFRP & 12.23 & 66.8 \\
\hline 145 & $\mathrm{C} 40-\mathrm{MO} 2 \%$ & 40 & 2 & - & 12.02 & 46.7 \\
\hline 146 & $\mathrm{C} 40-\mathrm{MO} 2 \%$ & 40 & 2 & - & 1.98 & 66.8 \\
\hline 147 & $\mathrm{C} 40-\mathrm{MO} 2 \%$ & 40 & 2 & - & 11.96 & 66.8 \\
\hline 148 & C40-CFRP-MO2\% & 40 & 2 & CFRP & 12.14 & 46.7 \\
\hline 149 & C40-CFRP-MO2\% & 40 & 2 & CFRP & 12.29 & 66.8 \\
\hline
\end{tabular}




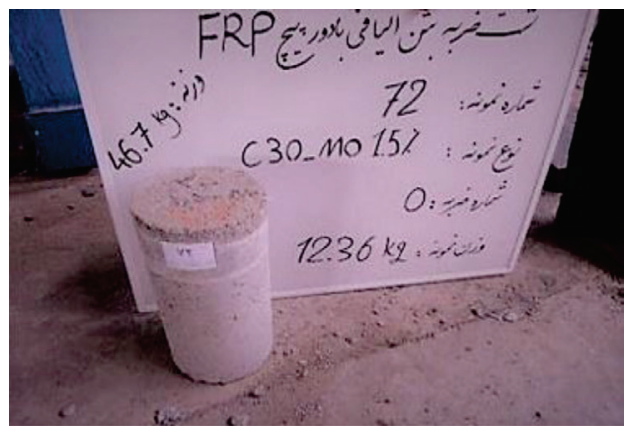

(a)

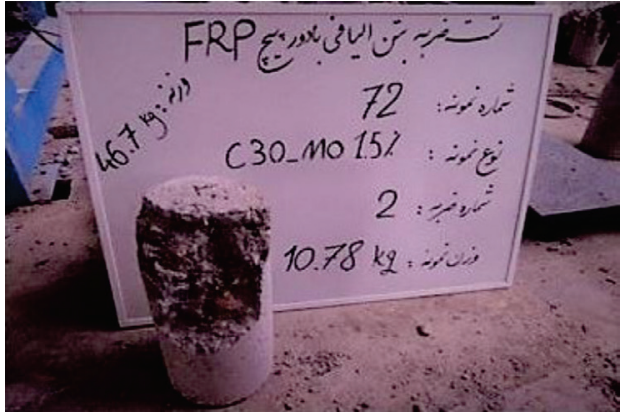

(c)

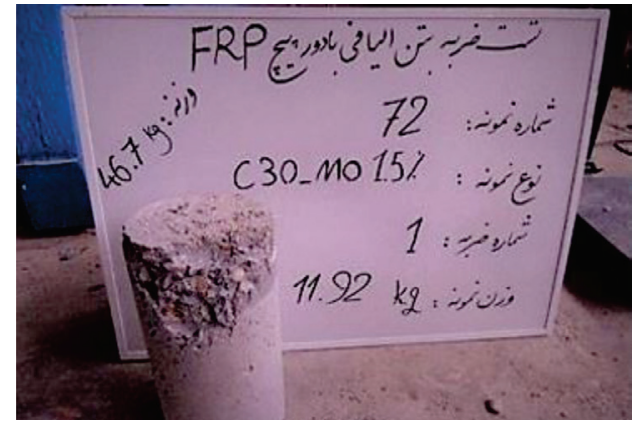

(b)

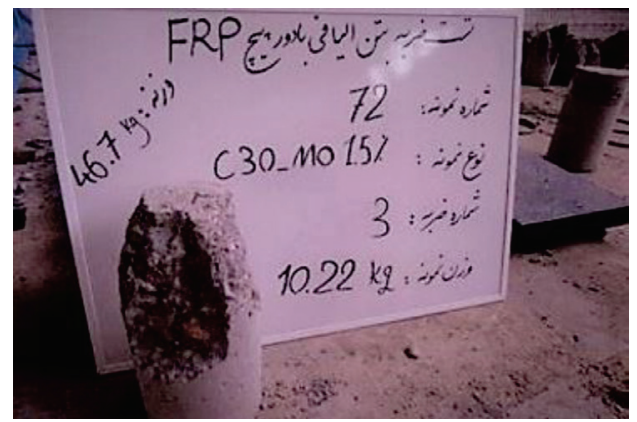

(d)

Fig. 5 C30 specimens with the $1.5 \%$ fibers: a) before impact, b) after the first impact, c) after the second impact, and d) after the third impact

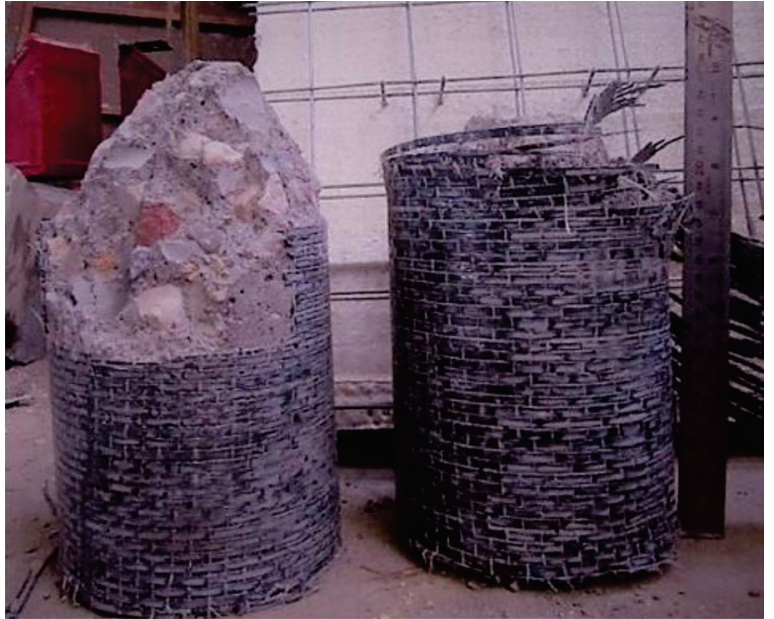

Fig. 6 Rupturing of the CFRP wrapping

with the damages on their upper portions which directly faced impacts. In the confined specimens, the damages were observed only in their upper portions. The confined specimens usually were destructed after layer-bylayer CFRP rupturing (or debonding) by imposing more impacts on them and partially destroying the confinement in the specimens. Therefore, the dominant failure mode of the specimens with CFRP wrapping was CFRP rupturing (or debonding). On the other hand, there were no such destructions as the destruction of the entire specimen, the separation of a large part of the specimen, or the halving of the specimen in the confined specimens. In the confined specimens, the destruction of the specimens often happened layer by layer and from top to bottom.

Fig. 7 and Fig. 8 illustrate the impact numbers corresponding to the destruction state of the specimens. First, the observations showed that the impact numbers of the specimens increased by an increase in the compressive strengths of the specimens, for example, the impact numbers of the C20, C30, and C40 specimens under the $46.7 \mathrm{~kg}$ weight-dropping were 3, 4, and 5. Moreover, the impact numbers of the specimens were 2, 2, and 3 for the $\mathrm{C} 20, \mathrm{C} 30$, and C40 specimens under the $66.8 \mathrm{~kg}$ weight-dropping. This process was repeated in all the confined and unconfined FRC specimens with the different steel fiber content ratios. Secondly, it was observed that the impact numbers of the specimens did not significantly vary using the $1.5 \%$ fibers in the $\mathrm{C} 20, \mathrm{C} 30$, and $\mathrm{C} 40$ specimens under both the 46.7 and $66.8 \mathrm{~kg}$ weight-dropping in comparison to the impact numbers of the specimens with the $1 \%$ steel fibers. The impact numbers of the $\mathrm{C} 20, \mathrm{C} 30$, and C40 specimens using the $1 \%$ and $1.5 \%$ steel fiber ratios had $33 \%, 25 \%$, and $20 \%$ increase under the $46.7 \mathrm{~kg}$ weight impacts. These increase ratios in the case of imposing the $66.8 \mathrm{~kg}$ weights were $50 \%, 50 \%$, and $33 \%$ for the $\mathrm{C} 20, \mathrm{C} 30$, and $\mathrm{C} 40$ specimens. Furthermore, the impact numbers of the C20, C30, and $\mathrm{C} 40$ specimens with the $2 \%$ steel fiber ratios under 


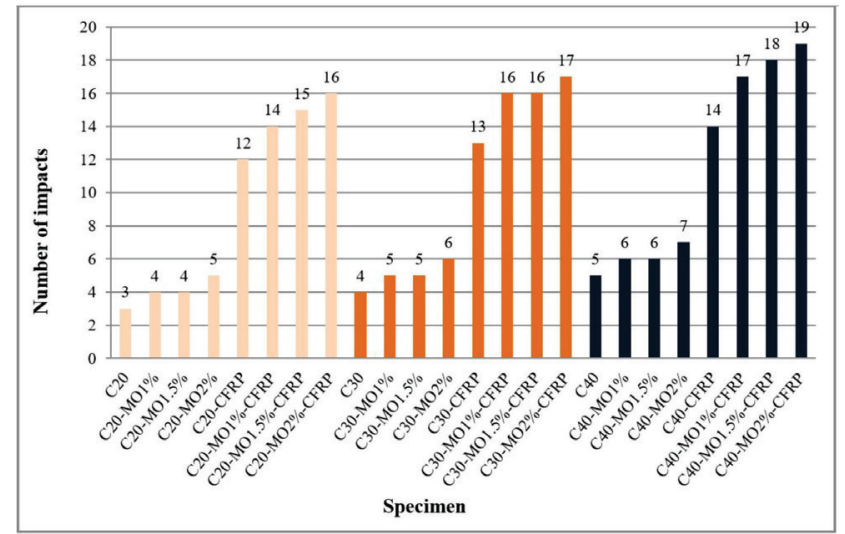

Fig. 7 Total impact numbers of the concrete samples subjected to the $46.7 \mathrm{~kg}$ weight-droppings

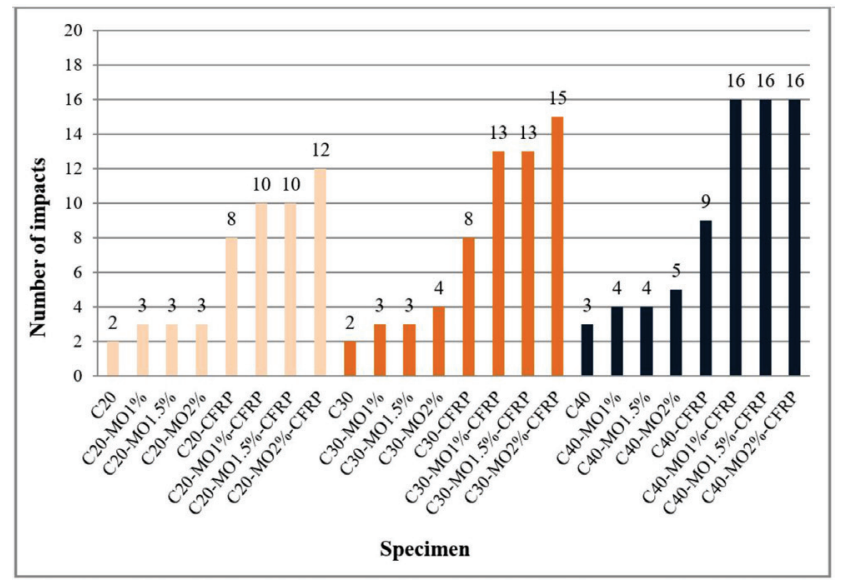

Fig. 8 Total impact numbers of the concrete samples subjected to the $66.8 \mathrm{~kg}$ weight-droppings

the $46.7 \mathrm{~kg}$ weight-releasing had $66 \%, 50 \%$, and $40 \%$ increase ratios, respectively. As for the $66.8 \mathrm{~kg}$ weightdropping, the increase in the impact numbers were $50 \%$, $50 \%$, and $66 \%$ for the $\mathrm{C} 20, \mathrm{C} 30$, and C40 specimens. This showed that the $2 \%$ fiber content ratio was very effective in the improvement of the impact resistance of the specimens.

As for the CFRP wrapping, the increases in the impact numbers of the specimens exposed to the $46.7 \mathrm{~kg}$ weight-releasing were $300 \%, 225 \%$, and $180 \%$ for the C20, C30, C40 specimens in comparison to the ones without the fibers, respectively. As for the $66.8 \mathrm{~kg}$ weight-releasing, these increase ratios were $300 \%, 300 \%$, and $200 \%$ for the C20, C30, C40 specimens, respectively. This means that the CFRP wrapping was much more effective in increasing the impact resistance of the concrete specimens than only using the steel fibers. The increases in the impact numbers of the CFRP-wrapped C20, C30, C40 specimens with the $1 \%$ steel fiber ratios under the $46.7 \mathrm{~kg}$ weight-dropping were $366 \%, 300 \%$, and $240 \%$. For the $66.8 \mathrm{~kg}$ weight-releasing, these increase ratios were $400 \%, 550 \%$, and $433 \%$ for the C20, C30, C40 specimens, respectively. The increase in the impact numbers of the CFRP-wrapped C20, C30, C40 specimens with the $1.5 \%$ steel fiber ratios were $400 \%, 300 \%$, and $260 \%$ in comparison to the specimens without the fibers and wrappings, respectively. As for the $66.8 \mathrm{~kg}$ weight-releasing, these increase ratios were also $400 \%, 550 \%$, and $433 \%$ for the C20, C30, C40 specimens, respectively. These increase ratios showed that using the $1.5 \%$ steel fibers along with the CFRP wrapping did not considerably affect the impact resistance of the specimens in comparison to the CFRP-wrapped specimens with the $1 \%$ steel fibers. The increased ratios for the CFRPwrapped $\mathrm{C} 20, \mathrm{C} 30, \mathrm{C} 40$ specimens with the $2 \%$ steel fiber ratios were also $400 \%, 325 \%$, and $280 \%$, respectively. These increase ratios were $500 \%, 650 \%$, and $433 \%$ for the C20, C30, C40 specimens (exposed to the $66.8 \mathrm{~kg}$ weight-releasing), respectively. It was shown that the application of the steel fibers along with the CFRP confinement was not as efficient as using just the CFRP-wrapping.

In conclusion, it was observed that the better efficient strategy to improve the impact behavior of the specimens under axial impact loading could be suggested as just the confinement rather than using the steel fibers with or without the CFRP wrapping. The CFRP confinement could improve the impact behavior of the specimens in different ways. One of these methods is related to Poisson's effect. Besides, the experimental observations showed that the lower-grade concrete specimens like the C20 ones had greater improvements in their impact behavior using steel fibers or CFRP wrapping. As shown in the figures below, the $\mathrm{C} 40$ concrete specimen was destroyed after the five impact numbers and the CFRP-confined C20 specimen with the $2 \%$ steel fibers was destroyed after the sixteen impact numbers. This issue demonstrated that the CFRP confinement and $2 \%$ steel fibers were more efficient than just an increase in the compressive strengths of the concrete specimens in the impact resistance. The optimum fiber ratios in the case of exposure to $46.7 \mathrm{~kg}$ weight were $2 \%$ for both the wrapped and unwrapped specimens. This ratio was $2 \%$ for the wrapped C20 and C30 specimens, $1.5 \%$ for the wrapped $\mathrm{C} 40$ ones, and $1 \%$ for the unwrapped $\mathrm{C} 20$ ones in the case of exposing to $66.8 \mathrm{~kg}$ weight.

\subsection{Weight-loss process}

As mentioned in the paragraphs above, the criterion to specify the destruction state of the specimens subjected to the impacts was the $30 \%$ weight-loss. This issue means 
that the damage evolution and impact behavior of the specimens can be controlled with respect to the weight-loss process of the specimens. Figs. 9-14 demonstrates the residual-to-initial weight ratios of the specimens during different impact numbers. In these figures, each diagram of the specimens had a sharper slope, faced more critical damages, and had worse impact resistance than the other ones. As demonstrated in Fig. 9 and Fig. 10, the specimens with the $2 \%$ steel fiber ratios had the best weight-loss process among the wrapped and unwrapped C20 FRC specimens subjected to the 46.7 and $66.8 \mathrm{~kg}$ weight-droppings. On the contrary, the $\mathrm{C} 20$ specimens with the $1 \%$ steel fiber ratios had a similar weight-loss process to the specimens without the steel fibers under the 46.7 and $66.8 \mathrm{~kg}$ weight-droppings. Therefore, the $1 \%$ steel fiber content ratio was not influential enough in the improvement of the weight-loss process of the specimens. This process was also observed in the CFRP-wrapped specimens. Regarding Fig. 11 and Fig. 12, the specimens with the $2 \%$ steel fibers amongst the wrapped and unwrapped C30 FRC specimens had the best impact resistance under both the 46.7 and $66.8 \mathrm{~kg}$ weight-droppings due to the lower weight-deterioration process. Furthermore, the wrapped and unwrapped specimens with the $1 \%$ steel fibers had nearly similar impact behavior to the wrapped and unwrapped C30 specimens

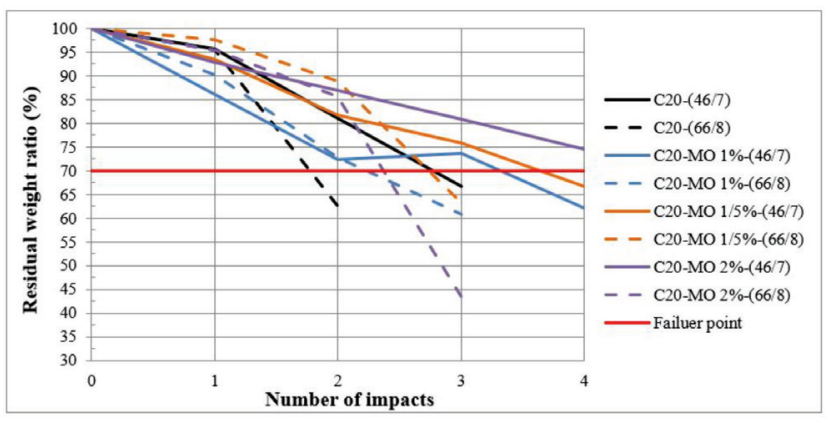

Fig. 9 Residual-to-initial weight ratios of the unwrapped C20 specimens

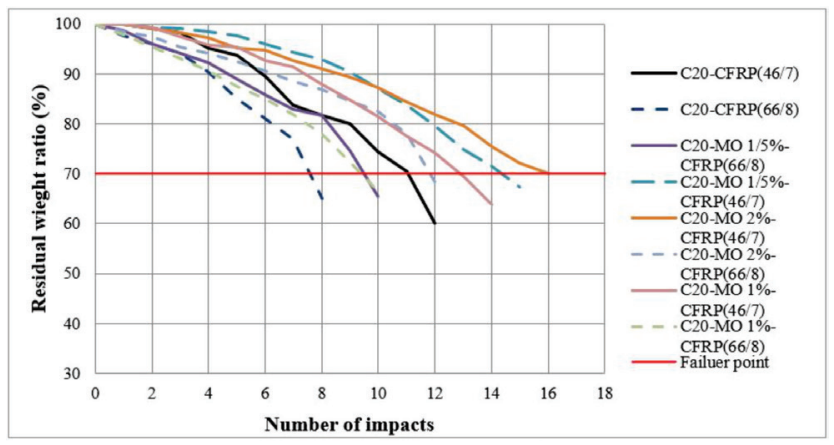

Fig. 10 Residual-to-initial weight ratios of the CFRP-wrapped C20 specimens without fibers, respectively. The same above-discussed legacy concerning the best amounts of the steel fiber ratios was observed in the wrapped and unwrapped C40 FRC specimens, i.e. the specimens with the $2 \%$ and $1.5 \%$ steel fibers had better impact resistance than the ones with the $0 \%$ and $1 \%$ steel fibers regarding their weight-loss process. Fig. 13 and Fig. 14 show the weight-loss process of the C40 FRC specimens subjected to the 46.7 and $66.8 \mathrm{~kg}$ weight-dropping.

\section{Conclusions}

RC structures can be subjected to impact loading and weight penetration during their service life. Thus, it is important to construct RC structures with acceptable impact resistance. In this paper, the influences of MEX200 (MO) fibers and bidirectional carbon fiber reinforced polymers (CFRPs) on the impact resistance of concrete specimens were studied. To this aim, 54 cylindrical concrete specimens with the compressive strengths of 20, 30, and $40 \mathrm{MPa}$ with different content ratios of macro-synthetic steel fibers $(0 \%, 1 \%, 1.5 \%$, and $2 \%)$ and bidirectional CFRP wrapping were constructed. Moreover,

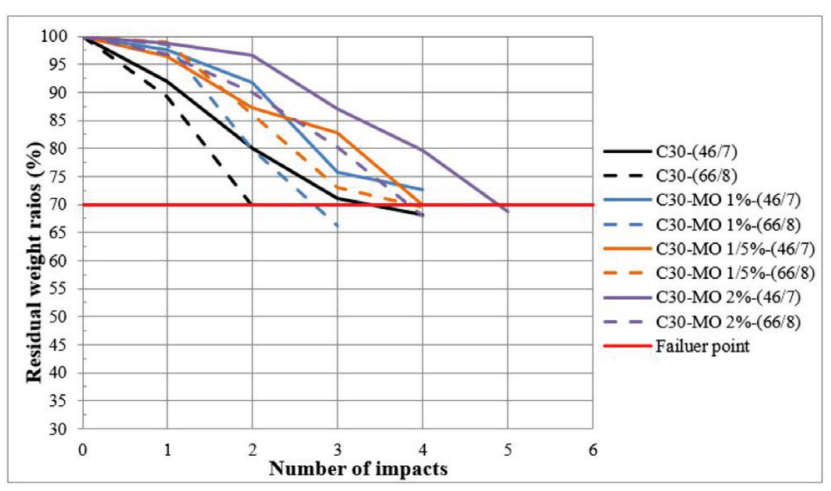

Fig. 11 Residual-to-initial weight ratios of the unwrapped C30 specimens

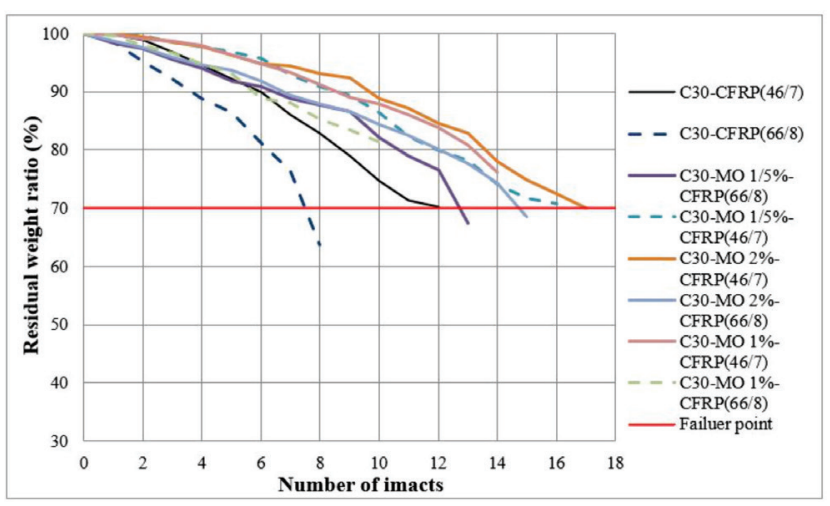

Fig. 12 Residual-to-initial weight ratios of the CFRP-wrapped C30 specimens 


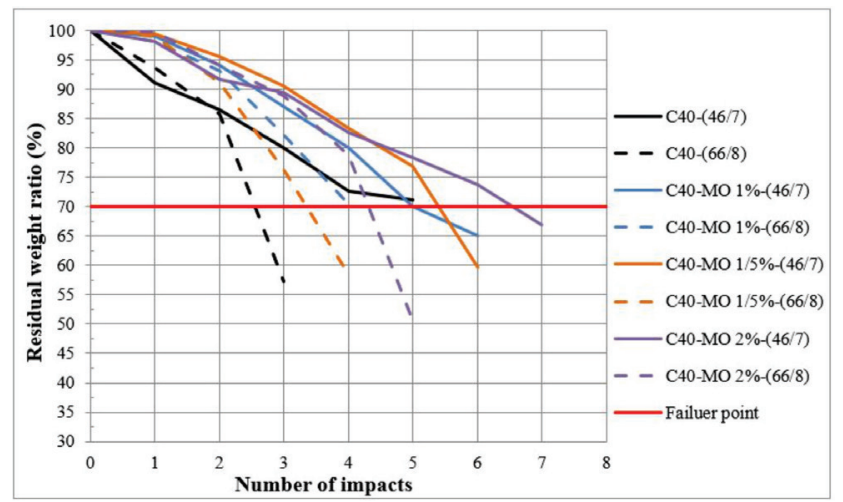

Fig. 13 Residual-to-initial weight ratios of the unwrapped C40 specimens

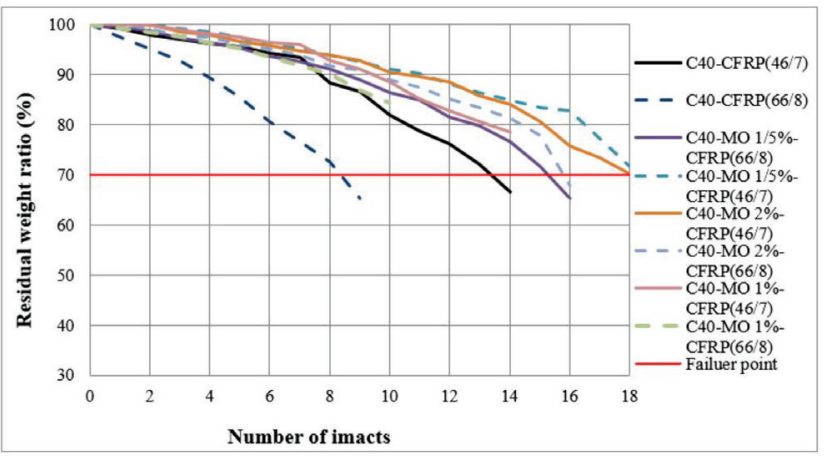

Fig. 14 Residual-to-initial weight ratios of the CFRP-wrapped C20 specimens

half of these specimens were tested with CFRP wrapping. The CFRP sheets were bonded to the concrete specimens by applying resins. The specimens were exposed to weight dropping which was made of cast iron. The concrete specimens were put on the strong floor under the iron weights

\section{References}

[1] Kheyroddin, A., Mirrashid, M., Arshadi, H. "An Investigation on the Behavior of Concrete Cores in Suspended Tall Buildings", Iranian Journal of Science and Technology, 41, pp. 383-388, 2017.

https://doi.org/10.1007/s40996-017-0075-y

[2] Arshadi, H., Kheyroddin, A., Naderpour, H., Kioumarsi, M. "Experimental study on the failure traits of frames with highstrength reinforcements", International Journal of Materials Science and Engineering (IJMSE), 2020. (Accepted for publication June 2020) (in press)

[3] Arshadi, H., Kheyroddin, A., Naderpour, H. "Experimental research on the damage indices of reinforced concrete beam-column connections of rail bridges with high-strength reinforcements subjected to cyclic loading", Journal of Transportation Infrastructure Engineering, 5(3), pp. 51-70, 2019. (in Persian)

https://doi.org/10.22075/jtie.2019.16918.1361
(46.7 and $66.8 \mathrm{~kg}$ ). The weights were located to the top of the specimens by a rope at a height of $1.62 \mathrm{~m}$. The weights (weights) were released on the concrete specimens by cutting the ropes. Then, the weight of the specimens was measured and compared to their initial ones (related to before dropping). This process of weight dropping was continued until the destruction of the specimens (30\% weight loss) happened. The numbers of weight releases in which the $30 \%$ weight loss occurred (which were equivalent to their impact resistance) were recorded.

The experimental results demonstrated that the dominant failure mode of the specimens with CFRP wrapping was CFRP rupturing (or debonding). Moreover, the impact numbers of the specimens increased by an increase in the compressive strengths of the specimens. Two percent of fiber ratio $(2 \%)$ was a more effective ratio than the other ones in the impact resistance improvement of the specimens in either wrapped or unwrapped specimens. However, it was observed that CFRP wrapping was much more efficient in the impact resistance improvement of the concrete specimens than only using the steel fibers. As for using both the steel fibers along with the CFRP confinement, it was observed that this case was not as efficient and economical as using just the CFRP-wrapping. Thus, the better strategy to improve the impact behavior of the specimens under axial impact loading can be asserted as just the wrapping (confinement) rather than using the steel fibers with or without the CFRP wrapping. Besides, the lower-grade concrete specimens had greater improvements in their impact behavior using steel fibers or CFRP wrapping than the higher-grade concrete specimens.

[4] Arshadi, H., Kheyroddin, A., Naderpour, H. "An investigation into the behavior of special moment frames with high-strength reinforcement subjected to cyclic loading", Journal of Building Engineering, 26, Article No. 100905, 2019.

https://doi.org/10.1016/j.jobe.2019.100905

[5] Arshadi, H., Kheyroddin, A., Naderpour, H., Kioumarsi, M. "Experimental investigation into the failure process of exterior beam-column joints with high-strength reinforcements", IOP Conference Series: Materials Science and Engineering, 910, Article No. 012007, 2020.

https://doi.org/10.1088/1757-899X/910/1/012007

[6] Arshadi, H., Kheyroddin, A., Naderpour, H. "High-strength reinforcement effects on the seismic behaviour of beam-column joints", Proceedings of the Institution of Civil Engineers - Structures and Buildings, 2019.

https://doi.org/10.1680/jstbu.18.00225 
[7] Kheyroddin, A., Arshadi, H., Binaipur, F. "An Overview of the Effects of High-Strength Reinforcement (HSR) on the Intermediate Moment-Resisting Frames", AUT Journal OF Civil Engineering, 1(2), pp. 177-188, 2017. https://oi.org/10.22060/ceej.2017.12406.5207

[8] Arshadi, H., Kheyroddin, A., Naderpour, H., Haji, M. "Study of the damage indices of concrete members reinforced with high-strength steel", Structures and Buildings, 2020.

https://doi.org/10.1680/jstbu.20.00165

[9] Arshadi, H., Kheyroddin, A. "Shear lag phenomenon in the tubular systems with outriggers and belt trusses", Magazine of Civil Engineering, 86(2), pp. 105-118, 2019. https://oi.org/10.18720/MCE.86.10

[10] Bonin, K., Neumaier, C. "Polymer binder, impact on the pull-out force of macro fibers in sprayed concrete", 6th International Conference on Durability of Concrete Structures, ICDCS 2018, Leeds, UK, 2018, pp. 233-237.

[11] Huang, L., Gao, C., Yan, L., Yu, T., Kasal, B. "Experimental and numerical studies of CFRP tube and steel spiral dual-confined concrete composite columns under axial impact loading", Composites Part B: Engineering, 152, pp. 193-208, 2018. https://doi.org/10.1016/j.compositesb.2018.07.008

[12] Kheyroddin, A., Arshadi, H., Ahadi, M. R., Taban, G. "The impact resistance of fibre-reinforced concrete with polypropylene and GFRP wrapping", In: 2nd International Conference on Aspects of Materials Science and Engineering, Chandigarh, India, March, 5-6, 2021. (conference paper in press)

[13] Kheyroddin, A., Arshadi, H., Salehzadeh, J. "Impact behavior of fiber-reinforced concrete with polypropylene fibers and carbon fiber reinforced polymers", ASTM Journal of Testing and Evaluation, 2021. (Accepted for publication January 2021) (in press)

[14] Arshadi, H., Izadifard, R. A., Estekanchi, H. "The Comparison of the IDA and ET on Steel Structures Rehabilitated by Isolators", Journal of Rehabilitation in Civil Engineering, 2(2), pp. 46-62, 2014. https://doi.org/10.22075/jrce.2014.208

[15] Arshadi, H. "An overview on the concepts and methodologies of incremental dynamic analysis IDA ( with a single record and multiple records)", presented at The 2016 Structures Congress, Jeju Island, Korea, Aug. 28-Sept. 1, 2016.

[16] Khani, J., Bozorg, M., Zahrai, S. M. "Investigating Seismic Behavior of Reinforced Concrete Columns with SFRP Using Finite Element Method", American Journal of Engineering and Applied Sciences, 11(2), pp. 996-1004, 2018. https://doi.org/10.3844/ajeassp.2018.996.1004

[17] Upendra Mahendra, P., Parekh, P. A., Hirani, P. L., Kumar Shah, D. "Experimental Study of CFRP \& GFRP Strengthened Reinforced Concrete Beam in Flexure \& Shear", [pdf] International Research Journal of Engineering and Technology (IRJET), 5(3), pp. 20622067, 2018. Available at: https://www.irjet.net/archives/V5/i3/ IRJET-V5I3479.pdf

[18] Sohaib, N., Mamnoon, R., Sana, G., Seemab, F. "Using Polypropylene Fibers in Concrete to achieve maximum strength", In: Proceedings of the Eighth International Conference On Advances in Civil and Structural Engineering - CSE 2018, 2018, Kuala Lumpur, Malaysia, pp. $37-42$.

https://doi.org/10.15224/978-1-63248-145-0-36
[19] Guerini, V., Conforti, A., Plizzari, G., Kawashima, S. "Influence of Steel and Macro-Synthetic Fibers on Concrete Properties", Fibers, 6(3), Article No. 47, 2018. https://doi.org/10.3390/fib6030047

[20] Kazmi, S. M. S., Munir, M. J., Wu, Y.-F., Patnaikuni, I. "Effect of macro-synthetic fibers on the fracture energy and mechanical behavior of recycled aggregate concrete", Construction and Building Materials, 189, pp. 857-868, 2018. https://doi.org/10.1016/j.conbuildmat.2018.08.161

[21] Mousavi, T., Shafei, E. "Impact response of hybrid FRP-steel reinforced concrete slabs", Structures, 19, pp. 436-448, 2019. https://doi.org/10.1016/j.istruc.2019.02.013

[22] Sadraie, H., Khaloo, A., Soltani, H. "Dynamic performance of concrete slabs reinforced with steel and GFRP bars under impact loading", Engineering Structures, 191, pp. 62-81, 2019. https://doi.org/10.1016/j.engstruct.2019.04.038

[23] ASTM "ASTM D7136 / D7136M - 05Standard test method for measuring the damage resistance of a fiber-reinforced polymer matrix composite to a drop-weight impact event", ASTM International, West Conshohocken, PA, 2005. https://doi.org/10.1520/D7136_D7136M-05

[24] Zhang, H., Wang, L., Lingyu, B., Addae, M., Neupane, A. "Research on the impact response and model of hybrid basaltmacro synthetic polypropylene fiber reinforced concrete", Construction and Building Materials, 204, pp. 303-316, 2019. https://doi.org/10.1016/j.conbuildmat.2019.01.201

[25] Andrew, J. J., Srinivasan, S. M., Arockiarajan, A., Dhakal, H. $\mathrm{N}$. "Parameters influencing the impact response of fiber-reinforced polymer matrix composite materials: A critical review", Composite Structures, 224, Article No. 111007, 2019. https://doi.org/10.1016/j.compstruct.2019.111007

[26] Pham, T. M., Chen, W., Hao, H. "Failure and impact resistance analysis of plain and fiber-reinforced-polymer confined concrete cylinders under axial impact loads", International Journal of Protective Structures, 9(1), pp. 4-23, 2018. https://doi.org/10.1177/2041419617749600

[27] Mastali, M., Dalvand, A., Sattarifard, A. "The impact resistance and mechanical properties of the reinforced self-compacting concrete incorporating recycled CFRP fiber with different lengths and dosages", Composites Part B: Engineering, 112, pp. 74-92, 2017. https://doi.org/10.1016/j.compositesb.2016.12.029

[28] ACI "Report on Fiber Reinforced Concrete", American Concrete Institute, Farmington Hills, MI, USA, Rep. ACI 544.1R-96, 2002.

[29] Mastali, M., Dalvand, A., Sattarifard, A. R. "The impact resistance and mechanical properties of reinforced self-compacting concrete with recycled glass fibre reinforced polymers", Journal of Cleaner Production, 124, pp. 312-324, 2016. https://doi.org/10.1016/j.jclepro.2016.02.148 